\title{
Selection Models for the Internal Quality of Fruit, based on Time Domain Laser Reflectance Spectroscopy
}

\author{
C. Valero , M. Ruiz-Altisent , R. Cubeddu ; A. Pifferi ; P. Taroni ; A. Torricelli ; G. Valentini ; \\ D. Johnson ; C. Dover \\ Dpt. Ingenieria Rural. E.T.S.I. Agrónomos. Universidad Politécnica de Madrid, Av. Complutense sin. 28040 Madrid. Spain; \\ e-mail of corresponding author: cvalero(@irtu.etsia.upm.es \\ INFM-Dipartimento di Fisica and IFN-CNR, Politecnico di Milano, Piazza Leonardo da Vinci 32, 20133 Milan, Italy; \\ e-mail: rinaldo.cubeddu@fisi.polimi.it \\ East Malling Research, East Malling. Kent ME19 6BJ. UK; e-mail: David.Johnson(âjemr.ac.uk
}

\begin{abstract}
Time domain laser reflectance spectroscopy (TRS) was applied for the first time to evaluate internal fruit quality. This technique, known in medicine-related knowledge areas, has not been used before in agricultural or food research. It allows the simultaneous measurement of two optical characteristics of the sample: light scattering inside the tissues and light absorption. Models to estimate non-destructively firmness, soluble solids and acid contents in tomato, apple, peach and nectarine were developed using sequential statistical techniques: principal component analysis, multiple stepwise linear regression, clustering and discriminant analysis. Consistent correlations were established between the two parameters measured with TRS, i.e. absorption and transport scattering coefficients, with chemical constituents (soluble solids and acids) and firmness, respectively. Classification models were created to sort fruits into three quality grades ('low', 'medium' and 'high'), according to their firmness, soluble solids and acidity.
\end{abstract}

\section{Introduction}

Non-destructive measurement of fruit quality has been a primary and widely established research objective in recent years (Abbott, 1999; Chen \& Sun, 1991; Hakimn et al., 1999). M any different techniques have been developed and applied to measure quality parameters. Some of them are oriented to the detection of physical aspects of the samples (i.e. firmness, seeds, skin colour, size/shape, defects, damages) and the rest are focused on chemical detection (i.e. quantifying main components or chemical residues, using radiation absorption at certain wavelengths). One of the limitations of these techniques is that they can only detect one quality parameter, so they have to be combined with other sensors to obtain more complete information on fruit quality.

Among them, the techniques based on optical properties of tissues and chemicals, and the interaction between radiation and organic matter have been proven useful in many research laboratories (Bellon et al., 1993; Jordan et al., 1997; Kawano, 1994; Moons et al. 1997;
Gunasekaran et al., 1984). Light absorption in nearinfrared (NIR) spectroscopy is used for the quantification of internal chemical components of foods (Lammertyn et al., 1998; Yantarasri et al., 1997) . Absorbance can be deduced from light transmitted from one side of the sample to the opposite. However sometimes, as in the present experiment, it is more advantageous to work with the NIR equipment in a 'reflectance procedure'. In this case, either focusing the light beam towards the sample, or confining it using fibre optics up to the sample surface (as in the present work), light is passed through a point in the sample. Light suffers internal reflection and refraction while travelling through the tissues; a portion of it could be absorbed, transmitted deeper into the body or reflected backwards. As part of the light re-emerges, it can be measured using a bundle of fibre optics or a single one in contact with the sample surface, as it was our case. This measurement procedure is often called 'body reflectance' (Nattuvetty \& Chen, 1980; De Belie et al, 1999) although it is a combination of transmission, refraction and reflectance. 


\section{Notation}

\begin{tabular}{|c|c|c|c|}
\hline$A$ & $\begin{array}{l}\text { total titratable acidity of squeezed } \\
\text { juice, } m e q l^{-1}\end{array}$ & $F_{P}$ & $\begin{array}{l}\text { maximum force for the needle punc- } \\
\text { ture test, } N\end{array}$ \\
\hline$B$ & number of fruit batch & $n$ & number of measurements. \\
\hline$D$ & day of measurement & $s$ & $\begin{array}{l}\text { soluble solid content of squeezed } \\
\text { iuice }{ }^{\circ} \text { Brix }\end{array}$ \\
\hline$d_{P}$ & $\begin{array}{l}\text { the Magness-Taylor test, mm } \\
\text { deformation at maximum force for }\end{array}$ & $s_{M}$ & $\begin{array}{l}\text { slope (force/deformation) for the } \\
\text { Magness-Taylor test, } \mathrm{Nm}^{-1}\end{array}$ \\
\hline$E_{M}$ & $\begin{array}{l}\text { the needle puncture test, } \mathrm{mm} \\
\text { energy absorbed for the Magness- }\end{array}$ & $s_{P}$ & $\begin{array}{l}\text { slope (force/deformation) for the } \\
\text { needle puncture test, } \mathrm{Nm}^{-1}\end{array}$ \\
\hline$F$ & $\begin{array}{l}\text { Taylor test, } \mathrm{Nmm} \\
\text { energy absorbed for the needle punc- }\end{array}$ & $\mu_{a .600} \ldots \mu_{a .1000}$ & $\begin{array}{l}\text { absorption coefficient } \mu_{a} \text { at each wave- } \\
\text { length }(600-1000 \mathrm{~nm}), \mathrm{cm}^{-1}\end{array}$ \\
\hline$M$ & $\begin{array}{l}\text { ture test, } N \mathrm{~mm} \\
\text { maximum force for the Magness- } \\
\text { Taylor test, } N\end{array}$ & $\mu_{s, 600}^{\prime} \ldots \mu_{s, 1000}^{\prime}$ & $\begin{array}{l}\text { transport scattering coeficient, } \mu_{s}^{\prime} \text {, at } \\
\text { each wavelength }(600-1000 \mathrm{~nm}) \text {, } \\
\mathrm{cm}^{-1}\end{array}$ \\
\hline
\end{tabular}

The main limitation of the techniques that measure light transmission properties of organic matter is that they do not account for the coupling between absorption and scattering inside the tissue, when quantifying the intensity of re-emitted light. This means that it is not possible to measure intensity of absorption without having its value affected by the effect of scattering, and vice versa. This paper shows how the time domain laser reflectance spectroscopy (TRS) technique applied to fruits is capable of obtaining quantitative information of absorption and scattering independently with one local measurement of total reflected light, as it was stated in preliminary studies (Cubeddu et al., 1999; Cubeddu et al. 2001).

The most commonly used light sources in NIR equipment are tungsten lamps, which provide a satisfactory spectrum over the visible region (VIS) and NIR. Nevertheless, some trials have been done (Martin \& Fehér, 1996; Tu et al., 1995) with more powerful, monochromatic light sources such as lasers. In spite of the theoretical disadvantage of a laser system, which can only produce narrow spectra and may be expensive, its use presents unique characteristics, including the ability to be precisely adjusted and its coherent behaviour. Indeed, it has been noticed that NIR 'laser spectroscopy' can be used to estimate the firmness of the fruits (Duprat et al. 1995; Tu et al., 1995; McGlone et al. 1997; Han \& Lambert, 1998; De Belie et al., 1999).

On the other hand, to implement any NIR spectroscopic technique, specific wavelengths or narrow windows are usually identified as those most correlated with different chemical compounds, and a different area along the spectrum could be used to extract firmness information. Even though this is an advantageous procedure for the development of a sensor (it will be able to obtain more than one quality parameter at a time) the final equipment will have to cover a wide range of wavelengths, some for the chemical and some for the firmness estimations, respectively.

The present technique, TRS, uses only a reduced number of laser wavelengths, obtaining information both on the chemical composition of the tissue and on firmness, using the same wavelengths. This is feasible because this technique uses a property of light-matter interaction that has not been applied before on the measurement of fresh food properties: it measures the time that light needs to be transmitted through the fruit, and the amount of light exiting the sample.

\subsection{Time domain reflectance spectroscopy basic princi- ples}

Time domain reflectance spectroscopy is an optical technique developed for medical applications and related areas (Cubeddu et al., 1994a). It is useful, for example, to quantify photosensitive dyes injected to in vivo tissues, to locate tumours due to the differential optical properties of their tissues (Cubeddu et al. 1994b). It can be used to quantify chemical components inside samples and to detect tissues (or regions of a sample) with different structure and, therefore, it has potential as new technique for agricultural and food industry applications.

The time domain reflectance spectroscopy procedure provides a complete optical characterisation of a diffusive sample as it estimates (at the same time and independently) the light absorption inside the tissues and the scattering across them. The light source is a laser, monochromatic, but tuneable at several wavelengths, and with a very short pulse rate. The light is directed on to the surface of the fruit through the intact 


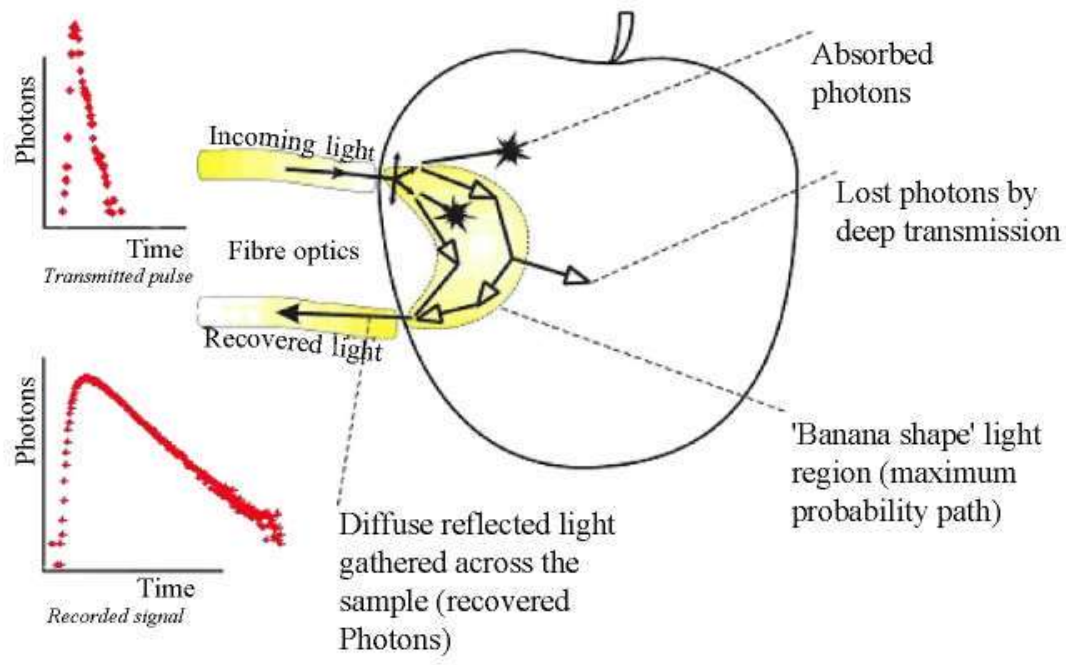

Fig 1. Schematic light paths during time domain reflectance spectroscopy measurements; some of the incoming photons by means of a light pulse are absorbed, and some transmitted towards deeper tissues; the photons collected by the returning fibre cross the sample along the maximum probability path and create a wider recovered signal

skin using fibre optics positioned perpendicularly to the central part of the fruit (Fig. 1). The light penetrates the tissues and part of it is reflected out of the sample at a particular region adjacent to the transmission point. This portion of reflected light was recovered with the collecting fibre optics placed at about $20 \mathrm{~mm}$ in parallel to the transmission ones. The three-dimensional region formed by the light which is capable of entering the collecting fibres (with a 'banana' shape) is constructed by the optical paths of the photons with greater probability of being recovered after suffering internal body reflection.

The working principle of the technique is the analysis of the attenuation and broadening of the time-distribution of the re-emerging light, and the correct interpretation with a proper theoretical model. Unlike the previously mentioned optical techniques using laser, TRS is capable of registering a time-signal of the reemitted light by means of a photo-counting sensor and a time-acquisition board. After applying the light diffusion theory (Cubeddu et al., 1994a), a de-convolution signal is obtained (Fig. 2), and two coefficients are calculated: the absorption coefficient $\mu_{a}$ and the transport scattering coefficient $\mu_{s}^{\prime}$. The working hypothesis of the present work was that light absorption could be correlated with soluble solid content or acidity (especially in the NIR region), and the scattering coefficient could be useful to estimate firmness, at the same time. This main advantage compared to other traditional spectroscopic techniques, which are only able to register the global attenuation spectrum, provide opportunities for applying this new measurement method in the food industry.

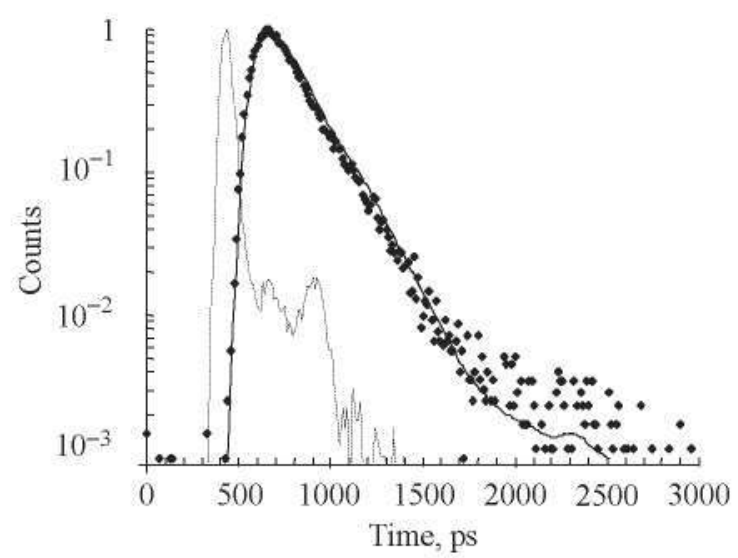

Fig 2. Typical data points (৬) acquired with time domain reflectance spectroscopy on an intact fruit, lighting with a $970 \mathrm{~nm}$ laser; number of photons (counts) recovered each moment are represented; system function response (_ - ) and curve fitted to data (-) using the diffusion theory are also shown (Cubbedu et al., 1999)

The objectives of the experiments carried out within this work were: (1) to study the applicability of a new optical technique, TRS, to measure internal fruit quality non-destructively (firmness, soluble solids content and titratable acidity); and (2) to develop fruit quality estimation models based on TRS parameters, and test their performance.

To achieve these objectives, it is necessary to measure a large amount of samples for a representative database to study the links between the optical TRS parameters and destructive tests used as reference, and then carry out modelling for the adjustment of such links between 
the TRS variables and the fruit quality parameters, for each species of fruit.

\section{Procedures}

\subsection{Plant material}

Over a period of $3 \mathrm{yr}(1996,1997,1998)$ a series of experiments were conducted by the Polytechnic University of Madrid (UPM) research group in close cooperation with the Physics Department at the Politecnico di Milano, Milan. These measurements covered a wide range of samples, fruit species and maturity stages. The material sampled for these collaborative measurements was entirely acquired at the local markets of Milan, during the different measurement periods (February, July and November, see Table 1). Fruits were selected piece by piece to obtain, with respect to the quality parameters, higher variance between batches than within them. The TRS optical characterisation $\left(\mu_{a}\right.$, $\mu_{s}^{\prime}$ ), firmness, soluble solids and titratable acidity and of apples, peaches, nectarines and tomatoes have been measured on different occasions, to establish a wide database of optical and destructive parameters. Taking into account all measurements: the firmness ranges are $30-95 \mathrm{~N}$ (maximum force Magness-Taylor penetration test) for apple, 5-60 N for peach and nectarine, 0.5$2 \mathrm{~N} \mathrm{~mm}^{-1}$ (force/deformation in puncture with needle test) for tomato; the sugar ranges are $10-18^{\circ} \mathrm{Brix}$ in apple, $4^{\circ}$ Brix in peach and nectarine, and $3 \cdot 9-6 \cdot 2^{\circ}$ Brix in tomato; the acidity ranges are $20-140 \mathrm{meq}^{-1}$ in apple, $90-155 \mathrm{meql}^{-1}$ in peach and nectarine, and $31-$ $120 \mathrm{meq}^{-1}$ in tomato.

\subsection{Measurements and protocols}

Non-destructive tests (TRS measurements) were conducted on two opposite sides of each fruit. Then, destructive tests for firmness, sugar and acidity were carried out on the samples, performing one repetition on each side of the fruit. The data were analysed later to obtain the average value per fruit.

\subsubsection{Time domain reflectance spectroscopy measure-} ments

On each sample, TRS measurements were performed on both sides to register the optical response under sequential illumination with two lasers: a VIS laser, tuneable at 672,750 and $800 \mathrm{~nm}$; and a NIR laser, tuneable every $10 \mathrm{~nm}$ in the wavelength range $900-$ $1000 \mathrm{~nm}$. Diffuse reflected spectra of the fruits were acquired in the time domain. De-convolution of the signal (Fig. 2) was used to extract the internal optical
Table 1

All samples measured: species, varieties, number of individual fruits and test periods

\begin{tabular}{|c|c|c|c|c|}
\hline Fruit & $\begin{array}{c}\text { Total } \\
\text { samples }\end{array}$ & Variety & $\begin{array}{l}\text { Number of } \\
\text { fruits }\end{array}$ & $\begin{array}{c}\text { Test } \\
\text { period }\end{array}$ \\
\hline \multirow[t]{18}{*}{ Apple } & 493 & $\begin{array}{l}\text { Golden De- } \\
\text { licious }\end{array}$ & 30 & Nov96 \\
\hline & & & 30 & Feb97 \\
\hline & & & 30 & Feb 98 \\
\hline & & & 10 & Nov98 \\
\hline & & $\begin{array}{l}\text { Granny } \\
\text { Smith }\end{array}$ & 30 & Nov96 \\
\hline & & & 15 & Feb 97 \\
\hline & & & 30 & Feb98 \\
\hline & & & 10 & Nov98 \\
\hline & & $\begin{array}{l}\text { Starking } \\
\text { Delicious }\end{array}$ & 10 & Nov96 \\
\hline & & & 10 & Feb97 \\
\hline & & & 30 & Feb98 \\
\hline & & & 10 & Nov98 \\
\hline & & Top Red & 28 & Feb97 \\
\hline & & Jonagold & 10 & Feb97 \\
\hline & & & 30 & Nov98 \\
\hline & & $\operatorname{Cox}$ & 30 & Nov98 \\
\hline & & Fiesta & 30 & Nov98 \\
\hline & & Gala & & \\
\hline \multirow[t]{2}{*}{ Peach } & 110 & Yellow & 60 & July97 \\
\hline & & & 50 & July 98 \\
\hline \multirow[t]{2}{*}{ Nectarine } & 90 & White flesh & 40 & July97 \\
\hline & & & 50 & July 98 \\
\hline \multirow[t]{5}{*}{ Tomato } & 220 & Daniella & 50 & July97 \\
\hline & & & 50 & July98 8 \\
\hline & & $\begin{array}{l}\text { Marmande } \\
\text { type }\end{array}$ & 50 & July97 \\
\hline & & & 50 & July 98 \\
\hline & & Cherry & 20 & July97 \\
\hline
\end{tabular}

parameters from the data curve: absorption coefficient $\mu_{a}$ and transport scattering coefficient $\mu_{s}^{\prime}$. The system and methodology is described in detail in Cubeddu et al. (1999) and Cubeddu et al. (2001). Notation for TRS variables used in this study was the following: $\mu_{a, 600}$ to $\mu_{a, 1000}$ denote absorption coefficient at each wavelength $(600-1000 \mathrm{~nm})$, while $\mu_{s, 600}^{\prime}$ to $\mu_{s, 1000}^{\prime}$ stand for scattering coefficient at each wavelength.

2.2.2. Physical and chemical tests to measure fruit quality

To characterise the physical state of the samples, several tests can be applied to the fruit, which are able to typify different mechanical aspects (Barreiro \& 
Ruiz-Altisent, 1996). In this case, the selected mechanical (destructive) tests were as follows.

Needle puncture test: Using a Texture Analyser machine (Stable Micro Systems Ltd, model TAXT2; Surrey, UK), a cylindrical probe of $0.8 \mathrm{~mm}$ diameter, flat head, was applied through the skin of tomatoes at a speed of $20 \mathrm{~mm} \mathrm{~min}^{-1}$, up to $8 \mathrm{~mm}$ deep and retracted at the same speed rate. Two repetitions were performed on each tomato (number of measurements $n=220$ ), one per side. The following parameters were determined from the force/deformation curve: maximum force $\left(F_{P}\right.$ in $\left.\mathrm{N}\right)$, maximum deformation $\left(d_{P}\right.$ in $\mathrm{mm}$ ), slope ( $s_{P}$ in $\mathrm{N} \mathrm{mm}^{-1}$ ) up to the maximum puncture force, energy $\left(E_{P}\right.$ in $\mathrm{Nmm}$ ).

Magness-Tavlor penetration of the flesh: Carried out on apples, nectarines and peaches with the Texture Analyser, each sample side was firstly peeled locally before being pressed with the metallic cylinder $(8 \mathrm{~mm}$ of diameter and rounded head). The speed of penetration was $20 \mathrm{~mm} \mathrm{~min}^{-1}$ to a depth of $8 \mathrm{~mm}$. Two measurements were recorded per fruit, one on each side. A total of 492 apples were measured, 110 peaches and 90 nectarines. The maximum force $\left(F_{M}\right.$ in $\left.\mathrm{N}\right)$, maximum deformation ( $d_{M}$ in $\left.\mathrm{mm}\right)$, slope $\left(s_{M} \mathrm{~N} \mathrm{~mm}^{-1}\right)$ and energy $\left(E_{M}\right.$ in $\mathrm{Nmm}^{-1}$ ) were registered.

Chemical tests were also carried out on the samples.

Titration of total acid content: After extracting the juice from each side of the fruit with a squeezer, a known volume was filtrated and titrated with a solution of $0.1 \mathrm{~N}$ sodium hydroxide until a $\mathrm{pH}$ of 8.2 was reached. An automatic titrator was used (model TR85-T80, SchottGerate GmbH, Hofheim, Germany). The milliequivalents per litre of acid concentration were calculated for each sample side, and averaged for each fruit.

Refractometric index: Brix degrees (soluble solids content, SSC) were measured on the juice of the samples from both fruit sides using a digital, temperaturecompensated refractometer (model PR-101, Atago Co Ltd, Tokyo, Japan). The results were averaged. Refractometric index was used as an indicator of sugar content of the fruits.

\subsection{Statistical analysis}

Based on previous experience on data analysis and model creation (Ruiz-Altisent et al., 1994) a complete statistical analysis was followed, consisting of three steps.

1st Step: Principal component analysis (PCA) was used to establish the hypothetic relations between TRS and the quality measurements.

2nd Step: Clustering techniques were used to 'naturally group' fruits according to their quality.
Firmness, sugars and acidity variables were used to establish these groups.

3rd Step: Discriminant analysis (DA) was used to develop the models for estimation of firmness, sugar and acid content. The TRS coefficients were used as explicative variables in the classification models, trying to reproduce the "natural groups'.

\section{Results}

\subsection{Performance of the time domain reflectance spectro- scopy technique}

Penetration depth of the light into the tissue was measured in previous work (Cubeddu et al., 1999) and it is about $1 \mathrm{~cm}$ deep into a thin-skinned fruit, such as an apple. Therefore, the quality attributes measured by the TRS match only a portion of fruit flesh contained in the corresponding volume which, in many cases, can be representative of a whole fruit, or of a half fruit. As two measurements were done, one on each side, and then averaged, the values obtained during the present work are considered descriptive of the whole fruit.

The acquisition time for each TRS measurement takes approximately $3 \mathrm{~s}$, including positioning of the sample, signal acquisition and automatic TRS model fitting to calculate $\mu_{a}$ and $\mu_{s}^{\prime}$. As the whole measuring device is computerised and the light pulses are short (ca $1 \mathrm{ps}$ ), the signal acquisition and processing depends only on the electronic board performance and on the operator skills to place the fruit.

\subsection{Principal component analysis}

Initially, the PCA was carried out by including all the measurements and variables together. The summaries of these analyses are shown in Table 2, where the first two principal components (factors) extracted from each PCA are detailed. Values in the table are factor scores, which are equivalent to correlation coefficients between each quality variable and the factor itself; then, two variables highly correlated within one factor, will be correlated among them, too.

With this approach, the first notable result is that the variables incorporated in the analysis explain only $30 \%$ of the total variance contained in the database (last row of Table 2). This fact may indicate that the true links between the TRS light behaviour inside the fruit and its quality are not well known, and depend on uncontrolled sources of variation, not taken into account in these experiments.

Also, the results of these PCAs are conditioned by the amount of variables introduced in them, belonging to 
Table 2

Principal component analysis for each species, including firmness, time domain reflectance spectroscopy (TRS) coefficients, chenical and other accessory variables

\begin{tabular}{|c|c|c|c|c|c|c|c|}
\hline \multirow[t]{2}{*}{ Variables } & & \multicolumn{2}{|c|}{ Peach and nectarine } & \multicolumn{2}{|c|}{ Apple } & \multicolumn{2}{|c|}{ Tomato } \\
\hline & & Factor $I$ & Factor 2 & Factor $I$ & Factor 2 & Factor I & Factor 2 \\
\hline \multirow[t]{6}{*}{ TRS absorption } & $\mu_{0,672}$ & 0.56 & 0.42 & -0.35 & 0.52 & -0.22 & $-0 \cdot 11$ \\
\hline & $\mu_{0,750}$ & 0.32 & 0.10 & 0.86 & -0.15 & 0.26 & 0.80 \\
\hline & $\mu_{t, 818}$ & 0.45 & 0.26 & 0.89 & -0.18 & -0.21 & $-0 \cdot 13$ \\
\hline & $\mu_{t, 900}$ & -0.08 & 0.49 & 0.80 & $-0 \cdot 19$ & -0.30 & 0.45 \\
\hline & $\mu_{a, 950}$ & 0.42 & 0.35 & 0.92 & -0.18 & -0.17 & 0.47 \\
\hline & $\mu_{a, 1000}$ & $0 \cdot 16$ & 0.48 & 0.00 & 0.09 & -0.02 & -0.01 \\
\hline \multirow[t]{6}{*}{ TRS scattering } & $\mu_{s, 672}^{t}$ & 0.44 & -0.62 & 0.81 & -0.24 & 0.49 & 0.43 \\
\hline & $\mu_{s, 750}^{\prime}$ & 0.70 & -0.46 & 0.94 & -0.07 & 0.41 & 0.78 \\
\hline & $\mu_{s, 818}^{t, / 50}$ & 0.67 & -0.45 & 0.88 & -0.13 & -0.25 & -0.44 \\
\hline & $\mu_{s, 900}^{\prime, 818}$ & 0.80 & -0.22 & 0.91 & -0.13 & -0.30 & 0.36 \\
\hline & $\mu_{s, 950}^{t, 900}$ & 0.80 & -0.12 & 0.89 & -0.15 & -0.55 & 0.09 \\
\hline & $\mu_{s, 1000}^{t}$ & 0.79 & $-0 \cdot 14$ & 0.20 & 0.01 & -0.28 & $0 \cdot 16$ \\
\hline \multirow[t]{4}{*}{ Firmness (Magness-Taylor) } & $F_{M}$ & 0.68 & 0.55 & 0.74 & 0.14 & - & - \\
\hline & $d_{M}$ & 0.65 & 0.58 & -0.33 & $-0 \cdot 14$ & - & - \\
\hline & $E_{M}$ & 0.63 & 0.56 & 0.49 & 0.07 & - & - \\
\hline & $s_{M}$ & 0.70 & 0.52 & 0.81 & 0.19 & - & - \\
\hline \multirow[t]{4}{*}{ Firmness (needle puncture) } & $F_{P}$ & - & - & - & - & $-0 \cdot 70$ & 0.32 \\
\hline & $d_{P}$ & - & - & - & - & -0.16 & -0.22 \\
\hline & $E_{P}$ & - & - & - & - & -0.47 & -0.01 \\
\hline & $s_{P}$ & - & - & - & - & -0.39 & 0.41 \\
\hline Acidity & $A$ & -0.05 & $0 \cdot 61$ & 0.31 & -0.11 & -0.90 & -0.11 \\
\hline Sugar content & $S$ & -0.37 & 0.27 & 0.26 & -0.01 & $-0 \cdot 66$ & 0.05 \\
\hline Batch & $B$ & -0.31 & 0.13 & -0.55 & -0.11 & -0.13 & 0.13 \\
\hline Day & $D$ & -0.50 & -0.43 & 0.94 & $-0 \cdot 19$ & 0.37 & 0.75 \\
\hline Explained variance & & $9 \cdot 65$ & 6.82 & $11 \cdot 55$ & $4 \cdot 66$ & $8 \cdot 13$ & $3 \cdot 68$ \\
\hline Explained variance, \% & & 33.29 & 23.52 & 38.48 & $15 \cdot 53$ & $28 \cdot 03$ & 12.71 \\
\hline
\end{tabular}

For each fruit, only the first and second principal components (Factors 1 and 2) are shown; values are factor scores (equivalent to correlation coefficients); highest relations are marked (bold).

$\mu_{a, 600} \ldots \mu_{a, 1000}$. absorption coefficient at each wavelength $(600-1000 \mathrm{~nm}) ; \mu_{s, 600}^{\prime} \ldots \mu_{s, 1000}^{\prime}$. transport scattering coefficient at each wavelength $(600-1000 \mathrm{~nm}) ; F_{M}$, Magness-Taylor maximum force; $d_{M}$, Magness-Taylor deformation; $E_{M}$. Magness-Taylor absorbed energy; $s_{M}$, Magness-Taylor slope; $F_{P}$, needle puncture test maximum force; $d_{P}$, needle puncture test deformation; $E_{P}$, needle puncture test absorbed energy; $s_{P}$, needle puncture test slope; $S$, soluble solid content; $A$, acidity of squeezed juice; $B$, number of fruit batch; $D$, day of measurement.

specific information groups; for example, if too many firmness variables are included, compared to the chemical content variables, the results are biased to the 'firmness information'. Nevertheless, some trends could be traced and the correlation coefficients found in the first PCA are strong enough to develop estimation models.

\subsubsection{Peach and nectarine}

Peach and nectarine were analysed together, as their rheological and chemical behaviour was similar, and rather different with respect to the rest of the fruit species. From a botanical point of view, they belong to the same specie, and can be considered physiologically similar. In view of the PCA results, considering all their measurements together, without distinction of variety type, side or batch, most of the firmness variables
(Magness-Taylor force, deformation, energy and slope) show clear correlation (Table 2, peach factor 1: factor scores $\approx$ coefficient of determination $R^{2}>0.63$ ) with the scattering at $750 \mathrm{~nm}$ and higher wavelengths. Factor 2 of the PCA groups TRS scattering at $672 \mathrm{~nm}$ and titratable acidity, but with low correlation $\left(R^{2}\right.$ of 0.61 , $0 \cdot 62$ ).

\subsubsection{Apple}

In an analogous way, considering all the measurements together, clear correlation is found (Table 2, apple factor 1: factor scores $\approx R^{2}$ from 0.74 to 0.94 ) between firmness variables (Magness-Taylor force and slope) and TRS scattering variables (at $672-950 \mathrm{~nm}$ ). Variable $D$ (day of measurement) is also present in a strong way in factor $1\left(R^{2}=0.94\right)$, which may be due to the fact 
that certain days, firmer samples were measured than on other days.

\subsubsection{Tomato}

As in the previous cases, considering all the measurements together, without distinction of varietal type, side or batch, correlation higher than 0.8 is found between many firmness variables (puncture) and scattering at 750 and $800 \mathrm{~nm}$ (Table 2, tomato factor 1), specially when running a separate PCA with TRS variables and firmness parameters alone. Factor 1 also shows correlation between the same firmness variables, acids and sugars $\left(R^{2}=0.66\right.$ and 0.90$)$. Factor 2 groups TRS absorption and scattering at $750 \mathrm{~nm}$, and variable $D$, which may indicate that samples with very different optical properties were measured in different dates.

\subsection{Clustering}

Having observed the important correlations between TRS parameters and fruit quality variables, the next step was the creation of 'natural' fruit groups (clusters) according to their internal quality (firmness, sugars and acids). The final purpose for these new groups was to develop estimation models capable of recreating the ascription of each sample to its correspondent quality group.

This methodology was used for each species, forming a set of clusters for each quality attribute independently (firmness, sugars and acids). To create these sets, the $k$ means clustering method was used, which produces exactly $k$ different clusters of greatest possible distinction (StatSoft Inc., 2002). The computer process (Statistica'98, StatSoft Inc.) starts with $k$ random clusters, and then moves objects (samples) between these clusters: (1) to minimise variability within clusters; and (2) to maximise variability between clusters.

From this procedure, the whole database of fruits was re-distributed into clusters, more homogeneously than the initial batches, when considering the single quality parameter that was used to form each set of clusters.

Several trials were made with different numbers of two, three and five clusters (Table 3). The overall performance of the classification models was usually $10 \%$ worse when trying to discriminate between five clusters, than when classifying into three or two clusters, showing a logical behaviour. From our experience with packinghouses and producers, when a sensor in installed on a packingline, the sizer (classifier) is programmed with a reduced number of classes to avoid excessive multiplication of final categories and packages (i.e. three colour grades by four sizes by two sweetness grades = results in 24 quality grades, which have to be packaged
Table 3

Effect of the number of clusters on the classification ability of the models

\begin{tabular}{lccc}
\hline Apple variety & \multicolumn{3}{c}{ Classification, \% } \\
\cline { 2 - 4 } & 2 clusters & 3 clusters & 5 clusters \\
\hline Cox & 93 & 77 & 64 \\
Top Red & 64 & 68 & 57 \\
Jonagold & 98 & 75 & 62 \\
Fiesta & 90 & 66 & - \\
Granny Smith & 75 & - & 48 \\
Starking Delicious & 95 & 68 & 70 \\
Golden Delicious & 89 & 86 & 62 \\
Gala & 86 & 60 & 63 \\
\hline
\end{tabular}

Two different discriminant analysis classification models were developed for each apple variety using two and three firmness clusters, respectively; values indicate the percentage of wellclassified individuals for each 'variety $\times$ number of cluster' combination.

in a variety of boxes and nets). Some of the sugar sensors used nowadays work on a two-class basis (one threshold value, i.e. normal sweetness and 'extra sweet'), while online firmness sensors are frequently programmed to discard very hard and very soft fruit (a three-class basis, two thresholds). Finally, for this study, for a practical approach in a future application of the technique at the industrial/grower level, three clusters were considered to be adequate, establishing in that way three quality grades for each parameter: good quality, poor and medium.

\subsection{Discriminant analysis and classification models}

Once the fruits had been distributed into sets of quality clusters, the next step was to try and estimate and explain those clusters using the optical TRS information contained in the $\mu_{\alpha}$ and $\mu_{s}^{\prime}$ parameters; discriminant function analysis was used for this objective.

Different models were developed for each quality parameter and each fruit species (i.e. a classification model was developed to group apples according to their firmness level, without variety distinction). To create the models, this is the classification functions, only half of the database was used. Models were validated using the other half of the database. Cross validations were made also combining different subsets of the database.

In the summary tables presented (Tables 4-6), scattering and absorption variables in the VIS region were used to develop the models for firmness estimation, and TRS variables in the NIR area were used as explanatory variables for SSC and titratable acidity 
estimation. The percentage of samples correctly classified into three quality classes (i.e. a priori belonging to cluster $i$ and finally classified into class $i$ ) for each model is shown, as well as the performance of the validations. In these tables, the variable used to create the cluster for each quality attribute (extracted from the destructive tests) is also detailed, as are the number of TRS wavelengths corresponding to the absorption and transport scattering coefficients that form the nondestructive estimation model.
Firmness estimation using TRS can be achieved with performances of $81 \%$ well classified fruits for tomato, $77 \%$ for peach and $76 \%$ for apple, as shown in Tables 4-6, respectively. Sugar estimation scored $98 \%$ accuracy for tomato, $86 \%$ for peach and nectarine and $77 \%$ for apple, and for acidity level $98 \%$ of tomato samples, $84 \%$ of peach and nectarine and $74 \%$ of apple, were correctly classified.

Also, cluster descriptions given in the right part of each table (Tables 4-6) show the average value of the

Table 4

Summary of three classification models according to fruit quality attributes for tomato

\begin{tabular}{|c|c|c|c|c|c|c|c|}
\hline \multirow{2}{*}{$\begin{array}{l}\text { Fruit } \\
\text { quality }\end{array}$} & \multirow{2}{*}{$\begin{array}{l}\text { Number of } \\
\text { wavelengths in } \\
\text { the model, and } \\
\text { spectum }\end{array}$} & \multicolumn{4}{|c|}{ Cluster description (average $\pm S D$ ) } & \multicolumn{2}{|c|}{ Performance, $\%$} \\
\hline & & Cluster & $\begin{array}{c}\text { Puncture } \\
\text { slope }\left(s_{P}\right), \mathrm{N} \mathrm{mm}^{-1}\end{array}$ & $\begin{array}{c}S S C(S) \\
{ }^{\circ} \text { Brix }\end{array}$ & $\begin{array}{l}\text { Total acidity }(A) \\
\operatorname{meq} \Gamma^{-1}\end{array}$ & Classification & Validation \\
\hline \multirow[t]{4}{*}{ Firmness } & 3 VIS & & & & & 81 & 80 \\
\hline & & 1 & $0.5 \pm 0.15$ & & & & \\
\hline & & 2 & $1.4 \pm 0.25$ & & & & \\
\hline & & 3 & $2 \cdot 3 \pm 0 \cdot 35$ & & & & \\
\hline \multirow[t]{4}{*}{ Sugar } & 11 NIR & & & & & 98 & 84 \\
\hline & & 1 & & $3 \cdot 8 \pm 0.31$ & & & \\
\hline & & 2 & & $4.6 \pm 0.21$ & & & \\
\hline & & 3 & & $5.3 \pm 0.25$ & & & \\
\hline \multirow[t]{4}{*}{ Acidity } & 12 NIR & & & & & 98 & 89 \\
\hline & & 1 & & & $25 \cdot 6 \pm 4 \cdot 54$ & & \\
\hline & & 2 & & & $43.3 \pm 3.76$ & & \\
\hline & & 3 & & & $55.6 \pm 5.74$ & & \\
\hline
\end{tabular}

Each model estimates one attribute (firmness, as needle puncture test slope; sugars as "Brix; or acids as meq $1^{-1}$ ) independently, using absorption and scattering coefficients at several wavelengths; VIS. visible; NIR, near infrared; SSC. soluble sugar content; SD, standard deviation.

Table 5

Summary of three classification models according to fruit quality attributes for peach and nectarine

\begin{tabular}{|c|c|c|c|c|c|c|c|}
\hline \multirow[t]{2}{*}{ Fruit quality } & \multirow{2}{*}{$\begin{array}{l}\text { Number of } \\
\text { wavelengths } \\
\text { in the model, } \\
\text { and spectnon }\end{array}$} & \multicolumn{4}{|c|}{ Cluster description (average $\pm S D$ ) } & \multicolumn{2}{|c|}{ Performance, $1 / 0$} \\
\hline & & Cluster & $\begin{array}{c}\text { Magness-Tavlor } \\
\text { force }\left(F_{M}\right), N\end{array}$ & $\begin{array}{c}S S C(S), \\
" B r i x\end{array}$ & $\underset{\text { meq }^{-1}}{\text { Total acidity }}(A)$ & $\begin{array}{l}\text { Classifica- } \\
\text { tion }\end{array}$ & Validation \\
\hline \multirow[t]{4}{*}{ Firmness } & 3 VIS & & & & & 77 & 73 \\
\hline & & 1 & $4.9 \pm 2.8$ & & & & \\
\hline & & 2 & $24.2 \pm 7.3$ & & & & \\
\hline & & 3 & $53.0 \pm 9.2$ & & & & \\
\hline \multirow[t]{4}{*}{ Sugar } & $8 \mathrm{NIR}$ & & & & & 86 & 77 \\
\hline & & 1 & & $10 \cdot 8 \pm 0.4$ & & & \\
\hline & & 2 & & $12 \cdot 1 \pm 0 \cdot 3$ & & & \\
\hline & & 3 & & $13 \cdot 4 \pm 0.6$ & & & \\
\hline \multirow[t]{4}{*}{ Acidity } & $10 \mathrm{NIR}$ & & & & & 84 & 75 \\
\hline & & 1 & & & $90 \cdot 7 \pm 13.1$ & & \\
\hline & & 2 & & & $123 \cdot 2 \pm 8 \cdot 5$ & & \\
\hline & & 3 & & & $155.6 \pm 8.3$ & & \\
\hline
\end{tabular}

Each model estimates one attribute (firmness, as Magness-Taylor force; sugars as "Brix; or acids as meq $1^{-1}$ ) independently, using absorption and scattering coefficients at several wavelengths; VIS, visible; NIR, near infrared; SSC. soluble sugar content; SD, standard deviation. 
Table 6

Sumnary of three classification models according to fruit quality attributes for apple

\begin{tabular}{|c|c|c|c|c|c|c|c|}
\hline \multirow{2}{*}{$\begin{array}{l}\text { Fruit } \\
\text { quality }\end{array}$} & \multirow{2}{*}{$\begin{array}{l}\text { Number of } \\
\text { wavelengths } \\
\text { in the model, } \\
\text { and spectrmm }\end{array}$} & \multicolumn{4}{|c|}{ Chuster description (average $\pm S D$ ) } & \multicolumn{2}{|c|}{ Performance, $\%$} \\
\hline & & Chuster & $\begin{array}{l}\text { Magness-Tavlor } \\
\text { force }\left(F_{M}\right), N\end{array}$ & $\begin{array}{l}S S C(S) \\
{ }^{\circ} \text { Brix }\end{array}$ & $\begin{array}{l}\text { Total acidity }(A) \\
\text { meq }^{-}\end{array}$ & Classification & Valiation \\
\hline \multirow[t]{4}{*}{ Firmness } & 3 VIS & & & & & 76 & 74 \\
\hline & & 1 & $17.5 \pm 3.11$ & & & & \\
\hline & & 2 & $29.1 \pm 3.65$ & & & & \\
\hline & & 3 & $41 \cdot 2 \pm 4.46$ & & & & \\
\hline \multirow[t]{4}{*}{ Sugar } & 5 NIR & & & & & 77 & 71 \\
\hline & & 1 & & $11 \cdot 5 \pm 1 \cdot 0$ & & & \\
\hline & & 2 & & $14 \cdot 1 \pm 0 \cdot 9$ & & & \\
\hline & & 3 & & $17 \cdot 5 \pm 1 \cdot 3$ & & & \\
\hline \multirow[t]{4}{*}{ Acidity } & 11 NIR & & & & & 74 & 72 \\
\hline & & 1 & & & $41 \cdot 3 \pm 10 \cdot 1$ & & \\
\hline & & 2 & & & $70 \cdot 3 \pm 10 \cdot 2$ & & \\
\hline & & 3 & & & $114 \cdot 3 \pm 14.8$ & & \\
\hline
\end{tabular}

Each model estimates one attribute (firmness, as Magness-Taylor force; sugars as ${ }^{\circ}$ Brix; or acids as meq $l^{-1}$ ) independently, using absorption and scattering coefficients at several wavelengths; VIS, visible; NIR, near infrared; SSC. soluble sugar content; SD, standard deviation.

quality parameter used to form each cluster in every set of data. It can be seen that the measured ranges for the different quality attributes sampled on each fruit are wide enough to cover all the possible ripeness stages that can be found normally in retail market fruits. Thus, the models could be useful for a general purpose application of a segregating system, such us distinguishing early harvested fruits (firm, low sugar) from ripe fruits (softer, sweeter). For more precise applications, new models with an intra-varietal basis would require to be developed.

\section{Discussion}

The correlations found with this work and the developed models, demonstrate that the TRS technique presents a good potential for applicability in agricultural and food sciences to characterise internal properties of fruits and similar tissues.

With the present acquired data and the results of the PCA, the correlation between TRS coefficients and quality attributes seems to be low, so the modelling work requires to be focused towards classification models (non-continuous estimation).

This initial proposal detailing how to select samples has been shown to be efficient in the screening of the TRS methodology, to estimate quality parameters, because with the acquisition of non-homogeneous, retail market samples, high variations on quality parameters can be achieved easily. Now, to calibrate the technique and the models, in terms of validation, adjustment, repeatability, etc. more controlled samples need to be used to enhance the results. The final calibration of models can be developed by a training process for specific sets of fruits, prior to each measurement session; an appropriate software to recalculate the models and a systematic protocol need to be developed to carry out this calibration on a "daily basis".

The estimation models include laser variables of different wavelengths, and this may affect the development of a future industrial prototype device due to the need to incorporate into the system the ability either to change the wavelength or to select from a high number of lasers. This will result in a more complicated construction process and therefore increases costs. With the estimation models developed so far, the possibility of using only one wavelength is not feasible because the estimation errors would be too high.

The range of wavelengths used in the firmness models $(670,750$ and $800 \mathrm{~nm})$ is in the limit of the VIS region. The first of these three corresponds to the chlorophyll spectrum peak, and the other two are in a spectral region where almost no compound presents absorbing properties. These two wavelengths may be considered "far-visible' or just the beginning of NIR, by some authors. They could be useful either as reference measurements or scattering measurements.

The classification models (sugar \& acids) based on NIR TRS variables include too many wavelengths ( $>5$ ) but the percentage of well-classified fruits is similar than the VIS models. This may be due to the different regions where each chemical compound absorbs light along the spectrum, but it also may cause on the models an 
'over-learning' of the database, making more difficult future validations. More analysis is required in reducing the number of NIR wavelengths used, taking into account also that any future development of a NIR device must be focused towards simplicity and low cost.

It has been observed that estimation models for firmness are slightly better when introducing scattering and absorption coefficients, than when using only scattering. This can be due to some complementary effect of absorption on the firmness information revealed mainly by the scattering. On the other hand, models with both absorption and scattering variables, at one or several wavelengths, could be unstable and therefore be unreliable in future validations, due to varying relations between firmness and chemical composition. Thus models containing only scattering coefficients, in the case of firmness, indicates the advantage of maintaining the initial hypothesis (light dispersion related to hardness) to gain stability, although lower segregation ability may be achieved.

The measured ranges covered for each quality attribute must be taken into account, compared with the segregation ability. With the collected database for each fruit, the ranges in quality attributes are high enough to cover most of the possible ripeness stages that every fruit could have, but these three scales (firmness, sugar and acidity) were established combining samples from different varieties. When applying these classification models to one-variety data sets, the segregation ability may drop down dramatically, as the corresponding scales within that variety will be much lower than the general ones. A specific study of each variety must be carried out.

The decision on the number of clusters when developing the classification functions must be taken accordingly to the final use of the industrial device to be developed. For an environment with high segregational needs, five clusters may be established although the incorrectly classified samples will be more, unless better performance is achieved. For online applications, where the classification is done frequently within three quality grades (high/medium/low) or just a binary decision of pass/fail (in combination with other parameters: weight, size, defects), only three/two clusters are needed and the models developed so far are accurate enough.

\section{Conclusion}

Time domain reflectance spectroscopy (TRS) has been shown to be applicable for the optical characterisation of the internal properties of fruits. The analysis of visible and near-infrared data for apples, tomatoes and peaches indicates that the TRS technique can be used to predict firmness, soluble solids content and acidity. The results support the hypothesis that the scattering coefficient should relate to texture properties, while the absorption coefficient should be associated with chemical constituents. So is shown by the certain correlation between scattering values at the far-visible region $(750$ and $800 \mathrm{~nm}$ ) and several firmness variables on tomatoes, and peaches, as well as the correlation between near-infrared NIR wavelengths and soluble solids content and acidity. Further study is needed on the relations between the physical and chemical changes caused by ripeness in the fruits, and their effect in the transmission/absorption of the TRS light pulses. Further research is required to optimise the classification performance.

\section{Acknowledgements}

The authors would like to acknowledge the EU and Comunidad Autónoma de Madrid (Consejería de Educación y Cultura, Spain) for its financial support in the EC project FAIR CT96-1060 and the PhD grant, respectively.

\section{References}

Abbott J A (1999). Quality measurement of fruits and vegetables. Postharvest Biology and Technology. 15(3), 207-225

Barreiro P; Ruiz-Altisent M (1996). Propiedades mecánicas y calidad de frutos. Definiciones y medidas instrumentales. [Mechanical properties and fruti quality. Definitions and instrumental measurements.] Fruticultura Profesional, 77, $48-55$

Bellon V; Vigneau J L; Leclercq M (1993). Feasibility and performances of a new multiplexed, fast and low-cost fiberoptic NIR spectometer for the online measurement of sugar in fruits. Applied Spectroscopy, 47, 1079-1083

Chen P; Sun Z (1991). A review of nondestructive methods for quality evaluation and sorting of agricultural products. Journal of Agricultural Engineering Research, 49, 85-98

Cubeddu R; Musolino M; Pifferi A; Taroni P; Valentini G (1994a). Time-resolved reflectance: a systematic study for application to the optical characterization of tissues. IEEE Journal of Quantum Electronics, 30(10), 2421-2430

Cubeddu R; Musolino M; Pifferi A; Taroni P; Valentini G; Canti G (1994b). Absorption spectrum of hematoporphirin derivative in vino in a murine tumor model. Photochemistry and Photobiology, 60(6), 582-585

Cubeddu R; Pifferi A; Taroni P; Valentini G; Torricelli A; Valero C; Ruiz-Altisent M; Ortiz C (1999). Non-destructive measurements of the optical properties of fruits by means of time.resolved reflectance. International Biomedical Optics Symposium (BIOS), 9th International Conference on Near Infrared Spectroscopy. Verona, Italy. 145-148

Cubeddu R; Pifferi A; Taroni P; Valentini G; Torricelli A; Valero C; Ruiz-Altisent M; Ortiz C (2001). Nondestructive quantification of chemical and physical properties of fruits 
by time-resolved reflectance spectroscopy in the wavelength range $650-1000 \mathrm{~nm}$. Applied Optics, 40(4), 538-543

De Belie N; Tu K; Jansóck P; De Baerdenaeker J (1999). Preliminary study on the influence of turgor pressure on body reflectance of red laser light as s ripeness indicator for apples. Postharvest Biology and Technology 16, 279-284

Duprat F; Chen H; Grotte M; Loonis D; Pietri E (1995). Laser light based machine vision system for nondestructive ripeness sensing of golden apples. Proceedings of the Intemational Federation of Automatic Control Workshop on Control Applications in Post-Harvest and Processing Technology. (de Baerdemaeker J, ed), pp. 117-123. Ostende. Belgium

Gunasekaran S; Paulsen M R; Shove G C (1984). Spectrophotometric methods for nondestructive quality evaluation of biological materials. ASAE Paper No. 84-3049

Hakim A, Purvis A C; Voipio I; Pehu E; Khatoon M (1999). Use of different nondestructive techniques to evaluate vegetable quality. Proceedings of the International Symposium on Quality of Fresh and Fermented Vegetables. Seoul, Korea. Acta Horticulturae (ISHS) 483, 235-244

Han Y J; Lambert W E (1998). Application of laser beams to apple firmness measurement. Proceedings of International Federation of Automatic Control Workshop on Control Applications and Ergonomics in Agriculture. Athens. Greece, Sigrimis, N, Groumpos. P.P., (eds), Elsevier. $87-92$

Jordan R B; Osborne S D; Künnemeyer R; Seeley R J (1997). Harvest time prediction of eating time properties of kiwifruit using NIR transmission. Proceedings of Sensors for Nondestructive Testing: Measuring the Quality of Fresh Fruits and Vegetables NRAES-97, Orlando. FL. Published by Natural Resource, Agriculture, and Engineering Service, Ithaca, NY

Kawano S (1994). Non-destructive NIR quality evaluation of fruits and vegetables in Japan. NIR News, 5(6), 10-12
Lammertyn J; Nicolä $\mathrm{B}$; Ooms $\mathrm{K}$; De Smedt V; De Baerdemaeker J (1998). Non-destrutive measurement of acidity, soluble solid, and firmness of jonagold apples using NIR-spectroscopy. Transactions of the ASAE, 41(4), 1089-1094

Martin P A; Felér M (1996). Application on near-infrared diode lasers in atmospheric and on-line process emission monitoring. NIR News, 7(3), 10-12

McGlone V A; Abe H; Kawano S (1997). Kiwifruit firmness by near infrared light scattering. Journal of Near Infrared Spectroscopy 5, 83-89

Moons E; Dardenne P; Dubois A; Sindic $\mathbf{M}$ (1997). Nondestructive visible and NIR spectroscopy for the determination of fresh dates by near infrared spectrometry. Proceedings of Sensors for Nondestructive Testing: Measuring the Quality of Fresh Fruits and Vegetables NRAES-97, Orlando, FL. Published by Natural Resource, Agriculture, and Engineering Service, Ithaca, NY

Nattuvetty V R; Chen $\mathbf{P}$ (1980). Maturity sorting of green tomatoes based on light transmittance through regions of the fruit. Transactions of the ASAE, 23(2), 515-518

Ruiz-Altisent M; Barreiro P; García J L (1994). Nondestruetive quality measurement and modelling in fruits. International Agrophysics, 8, 445-453

StatSoft, Inc. (2002). Electronic Statistics Textbook. Tulsa, OK: StatSoft. Web: http://www.statsoft.com/textbook/ stathome.html

Tu K; De-Busscher R; De-Baerdemaeker J; Schrevens E (1995). Using laser beam as light source to study tomato and apple quality non-destructively. Proceedings of the Food Processing Automation IV Conference. ASAE, 528-536

Yantarasri, T; Kawano S; Sornsrivichai J; Chen P (1997). Nondestructive NIR technique for sugar determination in intact mango. Proceedings of the 5th International Symposium on Fruit. Nut, and Vegetable Production Engineering. Davis, USA, 15. 